\title{
TRANSFER OF TEACHER TRAINING SKILLS IN CLASSROOM
}

\author{
Tara Bahadur Thapa \\ Department of EPM, T.U., TRM Campus, Birgunj \\ thapasirı@gmail.com
}

\begin{abstract}
Teacher training helps to increase teaching and learning process in the classroom. Its impact in classroom situation brings a good result in all teaching learning process and children's overall development. However, in spite of the intensive teacher training, the public school's achievements seem poor day by day in the context of Nepal. Many factors play the role to transfer the training skills to the classroom successfully. The effect of training in teaching and learning denotes the betterment of overall situation of classroom activities. So this article highlights on the existing situation of teacher training and the transfer of its skills in the classroom.
\end{abstract}

\section{Keywords}

Teacher, training, intensive, competence, effectiveness, training skills.

\section{Introduction}

Teaching is a profession that requires specialized knowledge acquired through training and experiences. Without proper training of teacher we cannot imagine the effectiveness of classroom delivery. So, teacher training is a vital element in preparing skilled teacher who plays an important role in shaping the quality of classroom delivery. Teacher training is not for the sake of knowledge and certificate itself, it is to develop skills to use in classroom.

Ministry of Education (MOE) implemented a teacher-training project known as Primary Education Development Project (PEDP) with a financial support of Asian Development Bank (ADB) from 1992. PEDP helped in the establishment of National Center for Educational Development (NCED) along with nine Primary Teacher Training Centers (PTTCs) in different parts of the country in 1993. These PTTCs are known as Educational Training Centers (ETCs) these days. The project was designed to provide service training to school teachers. For this, there were Basic and Primary Education Project (BPEP), and Secondary Education Development 
Project (SEDP). NCED played a role of an umbrella institution for PTT and SEDP was made responsible for lower secondary and secondary level teacher training. NCED has taken initiative of delivering need based shortterm training to all teachers (Singh, 2007). It has connection with school sector reform program. The training is called Teachers' Professional Development (TPD) and it does not go quite contrary to previous 10-month competency based trainings but is supportive in enhancing the expertise level of secondary level teachers. It is fully practical and demand based. Needs of real field will be addressed in the package prepared by the trainers and thus training conducted for ten days.

Despite these efforts, classroom instruction has not been effective. Parents and his/ her child are not satisfied with the level and quality of public schools' achievement. People are raising the question on the quality of the public school. It means that there is a gap between public school's performance and student's needs, interests and the expectations (Kafle, Adhikari and Thapa, 2011). Various causes are influencing contributing on the ineffectiveness of the teachers' classroom activities, such as, absence of training, mastery of subject matter, teacher motivation, inadequate instructional materials, classroom environment, and political pressure. (Khaniya, 2006). The main objective of this article is to explore measures to improve the transfer of teacher training skills in the classroom.

\section{Methods}

The article is based on qualitative and quantitative information regarding transfer of skills of trained teachers into the classroom situation. All the lower secondary and secondary level teachers of eight restricted schools from Makawanpr and Parsa districts who had completed 10-month in-service teacher training under NCED including head teachers, 10 students per school and 25 percent of the guardians were samples of the study. Interview, questionnaires, document analysis, classroom observation, checklist were the tools used to collect necessary information. Information was collected by using the research tools. Trained teachers' classes were observed by using classroom observation checklist and qualitative information were recorded and interview with the head teachers and trained teachers were held by using checklist and semi-structured interview questions.

\section{Results and Discussion}

The primary data collected through different sources were analyzed. The results have been presented under the following heads: -

\section{Existing situation of transfer of teacher training skills}

The training process has not succeeded to bring out realization among the traineeteachers that planning for teaching and teacher has the duty to create conducive learning environment in the classroom. That may be reason why plan for teaching and preparation of instructional materials for lesson is non-existent in all the sample schools. Application of training in terms of commencing lesson, presenting subject matter, linking contents to students previous learning experiences, treating students with love and respect, asking questions, undertaking assessment during lesson, using clear and non-threatening language seem up to the satisfactory level. NCED (2003) stated some truths about skillful teachers such as be clear about the purpose of teaching, reflect on their own learning while teaching, be wary of standardized models and approaches, expect ambiguity, seek students' background, talk to colleagues and share experiences, trust their own instincts, create diversity in teaching, take risks when needed, acknowledge their own personality, balance support and challenge, recognize the significance of their own actions and view oneself as a helper of learning. Specially, trained teachers were not found to have developed adequate skills to 
create conducive learning environment and they had no enthusiasm. This shows that the teacher training had no significant effect and they need further support to enhance their classroom performance in these skills.

\section{Supporting and inhibiting factors of training transfer}

Certain training related factors seem responsible for not applying training skills in the classroom. They can be categorized as lack of proper planning to teacher training in the context of local level, lack of competency on the subject matter as well as toaddress practical problems in the classroom. 4 out of 8 teachers seemed confused with too many techniques being suggested in the training session. They point out that there was not sufficient time for practices and lack of adequate preparation and use of instructional materials during training sessions. The CERID study (2003) on classroom practices of trained teachers and found that even if trained teachers learned some new methods in the training situation, they were found using the new methods only when they believed the new method as superior to and easy to apply than the old one. Untidy school environment, poor classroom conditions, classes being run irregularly and not up full requirements, and teacher and students irregularities are some of the visible aspects of organizational and managements problems. Trained teachers are faced with the problem of the lack of opportunities for follow up professional development programs. Wagle (2010) suggested the main indicators are efficiency in education system, financial investment in education, percentage of trained teachers, etc. In the context of behavior indicators of teachers' burnout, he identified that teachers dominated class, did not have their lesson plan while teaching, were found coming late and leaving earlier from their schools, taught from the books, were found free in taking the responsibility of pupils' failure, used lecture method mostly in the class, did not assign homework, looked tired, less enthusiastic and passive while talking to them, had a good relation with new teachers and were not mostly pleased with their head teachers. In the case of female teachers, he also found additional matter that they are blamed by most of the people for their knitting work in school time.

Besides, non-training factors such as poor physical facilities of the schools, lack of instructional materials, lack of collaborative culture among teachers, lack of financial and educational material support to the children of disadvantaged group, weak monitoring and follow up support from District Education Officers, school head teachers, school supervisors and Resource person have been hindering transfer of training skills in the classroom.

\section{Recommendations}

The following recommendations have been made regarding teacher training skills:

a. Similarity of training with work situation: The teachers stated that the training environment was not similar to the work environment. Feasible techniques were not introduced and practiced to make the training situation similar to the work situation. It pointed out that the training situation should be made similar with the working situation for maximizing the training transfer.

b. Competence and preparation of teacher: The trained teachers mentioned low level of trainer credibility as a factor inhibiting transfer of teacher training in the classroom. Incompetence of train teacher or trainer is linked with the policy regarding trainers' qualification too. Therefore, the trainer must be competent, qualified, dedicated and perfect one to teach the teachers if we have to transfer the training skills to the classroom in maximum degree.

c. Coordination of training: The trainee has practices alone in school based training 
period in their schools. Neither help from their trainer nor support from their supervisors do they get during the practicing period, the teachers reported. It means that a strong coordination between training center, district education office and school should be established to raise the transfer of training skill level.

d. Training methods and practice: Teachers are likely not to use newer techniques/ methods if they are skeptical of the fact that these can really make a change, or improve the classroom delivery. Half of the head teachers stated that there was lack of practice on feasible teaching techniques during training. Feedback becomes very much crucial while practicing training skills. Therefore, it is important to ensure proper and consistent practice, discussion, and demonstration of skill during training if we want our training to be a fruitful one. It shows that there is a need of practiceoriented training programs to lift up the standard of transfer of training.

e. Workload: Teachers' preparedness for lessons largely depends upon the teachers' workload. The Education Regulation (2059 B. S.) has clearly provisioned that a school teacher has to teach minimum 24 hours in a week. However, in this study, it was found that majority of the teachers taught more than 24 hours (up to 40 periods) in a week. This showed that the workload should not be over to use skills in the classroom.

f. Head teacher's support: In this study, 5 of the 8 head teachers were found almost unfamiliar with the instructional leadership role. The interpretation of the meaning of the instructional leadership is limited to assigning tasks to the teachers and teaching their own classes. They expressed that general staff meetings occurred rarely. Other school events such as teacher workshops, seminars, and lectures programs were never organized. From the above discussion, it was found that head teachers' professional support to the trained teachers in using their acquired skills in the classroom situation is necessary.

\section{Conclusion}

The following conclusions were made to address the transfer of teacher training skills in the classroom:

1. The training process has not succeeded to bring out realization among the traineeteachers that planning for teaching is an important duty of a teacher, and teacher has the duty to create conducive learning environment in the classroom. So there is a need for establishing a baseline of skills to be transferred. It could be done using the framework, which includes professional teaching competencies, elements of professional competencies, indicators/criteria of effective practice in the element, evidences of effective practice, trainee activities and facilitator activities. Provide training to the trainers covering training delivery skills in the classroom.

2. Teachers has facing several problems lack of adequate preparation and use of instructional materials during training sessions so teachers should be provided instructional materials from the school. The government needs to increase such a small amount of money given for quality enhancement. Further, an equalizing fund should be established so that the communities can also contribute to such a fund for purchasing and constructing adequate instructional materials at local level.

3. The confusion with too many techniques being suggested in the training and low level of trainer credibility is also 
an inhibiting factor for transferring of teacher's training skills in the classroom situation. So teachers must be familiarized with feasible teaching techniques while training so that they can apply their acquired skills in the real classroom situation.

4. There was lack of proper and consistent demonstration, discussion and practice for the internalization of some concepts and practical use of the some skills during the training collaborative culture among teachers, lack of financial and educational material support to the children of disadvantaged group, weak monitoring and supervision system has been hindering transfer of training skills in the classroom. So teachers should have enough opportunity to demonstrate, discuss and practice different teaching skills during training under the guidance and supervision of trainers.

5. In most of the schools, there was no culture of sharing experiences, teamwork, and collaboration. They did not try to make discussion with the colleagues and head teachers when they were free. They did not get any support from the school supervisors. So teachers should have prepared transfer strategy or action plan with the help of colleagues and should be implemented in the school with regular monitoring and supervision of school head teachers.

\section{References}

CERID, (2003). Effective classroom teaching learning (phase 2 Transfer of teaching skills). Kathmandu: Author.

Kafle, B, Adhikari, N.P \& Thapa, T.B. (2011). Human resources management in education, (In Nepali) Kathmandu: Sunlight Publication.

Khaniya, T. R. (2006). New horizons in education in Nepal. Kathmandu: Kishor Khaniya.

NCED, (2003). Follow up study of teacher training program: A study report. Sanothimi: Author

Singh, G.B. (2007).Transfer of teaching skillsderivation from case. Journal of TESON 1, 53-62.

Wagle, M.P. (2010). Paradigm shift in teacher education. Academic Challenges, 1, 35-44. 